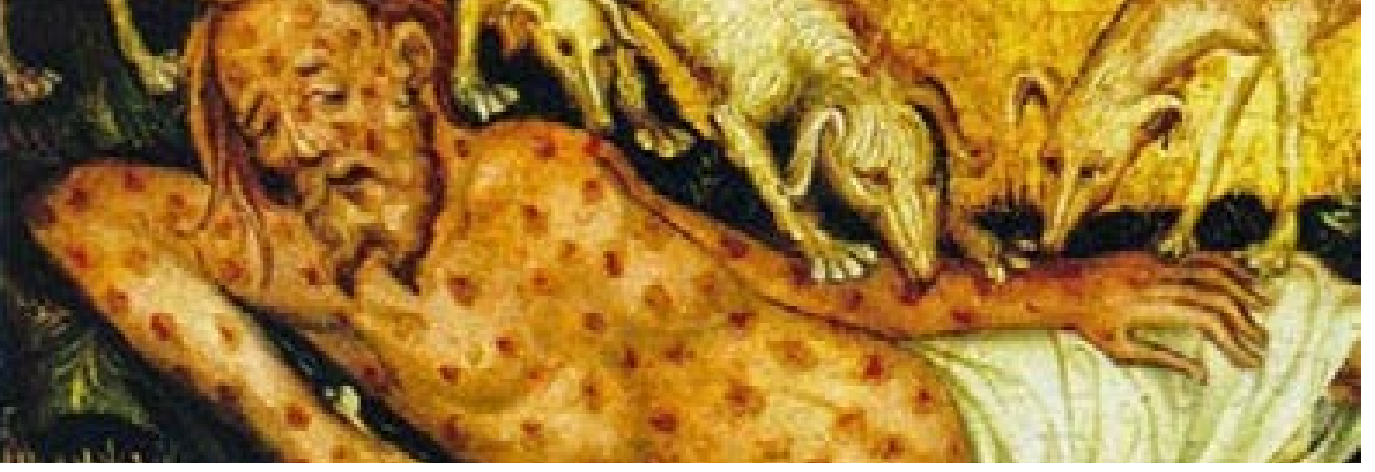

\title{
Lepra, muerte civil y exclusión de la comunidad en
} la Edad Media

Universidad Nacional de Córdoba, Argentina.

\section{Leprosy, civil death and exclusion from the community in Middle Ages}

\section{Resumen}

En este trabajo se plantea y critica la asimilación entre lepra y muerte civil que la historiografía suele asumir como dato del panorama jurídico bajomedieval. Se aborda así la compleja relación entre formas de exclusión de la comunidad y las ficciones del derecho, teniendo en cuenta las limitaciones de este tipo de operaciones jurídicas en la Baja Edad Media así como también la alta ambigüedad que caracteriza el tratamiento de los leprosos en este período.

\section{Palabras clave}

Lepra - muerte civil - derecho medieval - marginalidad.

\section{Abstract}

This paper raises and criticizes the assimilation between leprosy and civil death that historiography usually assumes as a datum of late medieval juridical horizon. The complex relationship between forms of exclusion of the community and the fictions of law is addressed, taking into account the limitations of this type of juridical operations in the late Middle Ages as well as the high ambiguity that characterizes the treatment of lepers in this period.

\section{Keywords}

Leprosy - civil death - medieval law - marginalization

Recepción de artículo: 11-11-2018

Aceptación del artículo: 6-5-2019

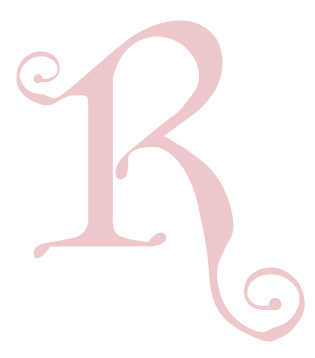


El derecho en tanto técnica social contempla el uso de distintos artificios entre los cuales se destaca el de la ficción. Su nota distintiva es la de actuar contra veritatem. Mientras que con la presunción el derecho se asegura una certidumbre en una situación incierta (asumiendo como verdadero lo que solamente es probable), con la ficción, en cambio, procede "como si" fuese cierta la situación contraria a la admitida como verdadera. Entre las ficciones que poblaban el mundo jurídico premoderno hallamos una particularmente interesante, la de la muerte civil que implicaba la implementación de la ficción de tener a alguien por muerto ('habere pro mortuo'): a efectos prácticos, las personas alcanzadas por este mecanismo debían ser consideradas muertas en lo que respectaba al manejo de su patrimonio o al ejercicio de la patria potestad.

En la Edad Media, esta figura se emplea en determinadas penas como la deportación o la condena ad metallum, los trabajos forzados en las minas del rey. Podemos observar, a modo de ejemplo, cómo se trata este instituto en la gran codificación legal que significó en el s. XIII la confección de las Siete Partidas de Alfonso X. En Partidas se describe esta 'manera que y ha de vna pena' por la que el condenado 'como quier que [...] non sea muerto naturalmente: tienen las leyes, que lo es, quanto a la honrra, e a la nobleza, e a los fechos deste mundo' ${ }^{1}$. El texto distingue en la muerte civil dos clases. En la primera se refiere a una condena perpetua a trabajos forzados que convierte al acusado en un 'sieruo de pena' ('como si diessen iuyzio contra alguno para siempre, que labrasse las obras del Rey: assi como lauores de sus castillos, o para cauar arena: o traerla a sus cuestas, o cauar en las minas de sus metales, o a seruir para siempre'). En la segunda, la nota distintiva la da la pena de destierro: 'quando destierran a alguno por siempre, e lo embian en algunas yslas, o en algund otro lugar cierto onde nunca salga: e le toman demas todos los bienes: e este atal es llamado en latin deportatus'. En ambos casos, la muerte civil supone la pérdida de la patria potestad ('desatase por ella el poder, que este atal ha sobre sus fijos, e salen porende de su poder') y la inhabilidad testamentaria ('non puede fazer testamento, e avn si lo ouiesse ante fecho, non valdria').

La expresión "muerte civil" fue acuñada por juristas medievales a partir de materiales brindados por diversos institutos del derecho romano como la interdicción de agua y fuego, la deportación, la servitudo poenae o la capitis deminutio ${ }^{2}$. Por otro lado, la construcción de esta figura en el mundo medieval encontró en el desarrollo jurídico de la excomunión un ámbito bien propicio. Pero se trata de una ficción que no se empleaba solo en clave penal. En efecto, también se recurría a ella para dar cuenta de cambios voluntarios de condición personal y es así que uno de los mayores desarrollos se dio en el contexto de la discusión en torno del estatuto jurídico de quienes se alejaban del mundo para ingresar a la vida monacal.

En este trabajo queremos centrarnos en una figura que la historiografía ha conectado tradicionalmente con la institución de la muerte civil como ejemplo de exclusión de la sociedad y de muerte en vida. Nos referimos a los leprosos cuya expulsión del seno de la comunidad encuentra incluso un momento de ritualización que funciona como una inversión del bautismo. Los sujetos detectados y confirmados como leprosos debían pasar por una ceremonia liminal antes de ser expulsados, la famosa "misa de leprosos", que fue en parte codificada en unos ordines de finales de la Edad Media y que fascinaron a los historiadores del s. XIX, acostumbrados a ver en el Medioevo un mix de irracionalidad y morbo. No existe un ordenamiento unificado pero en los distintos ordines (que pueden ser agrupados en familias) se rastrean unos pasos rituales que, de manera eficaz, producen la transformación del leproso en un muerto ${ }^{3}$. Sumando de distintos esquemas, hallamos, por ejemplo, los siguientes elementos: el sacerdote párroco anuncia el día de la ceremonia a la manera de un óbito; el leproso se arrodilla en un catafalco; se lleva adelante una misa de requiem con su específica liturgia y sus cantos; el enfermo efectúa su última confesión; se trasladan al cementerio y el leproso desciende en una fosa ya preparada donde recibe un determinado número de paletadas de tierra en la cabeza como simulacro de inhumación; se erige una cruz; se trasladan en cortejo hasta el borde de la localidad donde residirá en aislamiento el enfermo quien recibe unas últimas admoniciones acerca de su experiencia de purgatorio en la tierra.

Como decíamos, se trata de una ritualización que no es uniforme (incluso hay ordines que expresamente prohíben el desarrollo de una misa de difuntos en el conjunto de este ceremonial $)^{4}$ pero el sentido general es claro, tal como lo grafica la fórmula que declara el sacerdote: 'sis mortuus mundo, vivens iterum Deo's. Esta simulación de muerte representa, para Françoise Bériac, una traducción tardía al registro litúrgico de una situación jurídica ya establecida, que esta autora describe apelando a una cita de Philippe de Beaumanoir en su recolección y comentario a las costumbres de Beauvaisis (1283): aquel que 'devient meseaus, par quoi il convient qu'il lesse la compaignie des gens [...] si tost comme il est pris de cele maladie, il est mors quant au siecle'6.

Volveremos después sobre las referencias jurídicas que justifican en principio esta conexión entre lepra y muerte en vida. Anotemos ahora, sin embargo, que en este tipo de planteos legales y litúrgicos abrevaron los historiadores que estudiaron el mundo de la marginalidad en la Edad Media, el más famoso de los cuales, Robert Moore en su clásico libro sobre la formación de la sociedad de persecución a partir del s. XII, incluye a los leprosos en un conjunto de perseguidos (con los herejes, los judíos, los sodomitas, las prostitutas) que no tienen otro denominador común más que las instituciones que los persiguen y que acostumbran usar con ellos mecanismos y retóricas de alta plasticidad? ${ }^{7}$. Esta corriente ha leído la exclusión de los leprosos en clave política y no médico-sanitaria, insistiendo en la amplitud de afecciones cutáneas que eran identificadas como lepra en el mundo medieval (y en la tradición bíblica), de manera de revelar el factor político que supone la detección y confirmación de un individuo como leproso, operación que excede

1. Partidas IV.18.2. Las citas de Partidas siguen la edición de Gregorio López de 1555. Sobre la muerte civil en el derecho castellano, ver Vallejo 2004.

2. Borgmann 1972.

3. Bériac 1985.

4. Bériac 1985, califica de breve y tardía la difusión de los ordines al darse en el momento de regresión de la endemia y la contextualiza en el horizonte cultural posterior al ciclo de pestes tardomedievales, impregnado de elementos macabros. En este sentido, operan como un rito catártico por el cual los últimos leprosos hacen las veces de chivos emisarios del temor generalizado.

5. Merzbacher 1967, p. 29 y ss

6. Philippe de Beaumanoir 1900, pp. 326-327.

7. Moore 1989, pp. 59-81; Beriou 1991, pp. 68-69. 
a una visión exclusivamente médica.

Ahora bien, la historiografía sobre la lepra en la Edad Media de los últimos 25 años ha relativizado estos postulados, poniendo en duda la "muerte social" de los leprosos y recalibrando su nivel de segregación. La bibliografía más reciente no desconoce las menciones legales a una muerte en vida. Pero puede señalar un hecho evidente, el que se trate de menciones alejadas del ius commune, la principal y más rica tradición jurídica en el Occidente medieval y se pregunta por la efectividad de esa muerte social en función de la permanencia de contactos con el mundo de los sanos, e incluso de esa muerte civil, dando cuenta de la persistencia de algunas capacidades jurídicas.

Esta renovación de los estudios sobre la lepra medieval, que encuentra en François-Olivier Touati su mentor, busca explícitamente evitar ciertos estereotipos fundados en la particular imagen que el siglo XIX pergeñó sobre la Edad Media y que, a su criterio, los historiadores de la marginalidad medieval han recibido de forma acrítica ${ }^{8}$. De esta manera, se resignifican algunas imágenes clásicas de la cuestión como, por ejemplo, la lectura de la obligatoriedad de uso de las tabletas por parte de los leprosos, no en clave de separación con el mundo de los sanos sino también de convocatoria a la limosna, lo cual supone un acortamiento de las distancias con dicho mundo. Se ha cuestionado también la visión del leprosario como un lugar de internación obligatoria que efectivizara la exclusión de la sociedad, señalando que los reglamentos de disciplina interna de estos centros preveían la expulsión en caso de contravenciones graves, lo cual no supone una lógica carcelaria que encierra a toda costa sino más bien un sentido de pertenencia a una nueva comunidad y, en este punto, no es casual que esta historiografía recalque el carácter cuasi monacal de las leproserías 9 . Por último, también se rescata la labor de la arqueología, cuyo análisis de los cementerios de leprosos verificaría la infección de los restos con el Mal de Hansen, en clara contraposición con la idea de una construcción discursivo-política de los leprosos en tiempos medievales ${ }^{10}$.

Dado este contexto historiográfico, ¿qué se puede decir al respecto desde el análisis de las fuentes jurídicas? En primer lugar, debemos abandonar la idea de hallar unas referencias claras y sistemáticas sobre el tratamiento jurídico de la lepra en esta sociedad. Se evidencia una amplísima variedad de modalidades de exclusión que parecen haberse desarrollado en el mundo de las prácticas y que la doctrina no empalma necesariamente con sus referentes textuales.

Así, el papa Alejandro III, al legislar sobre la disolución o permanencia del matrimonio de los enfermos de lepra (en el Tercer Concilio Laterano de 1179$)^{11}$, refiere a la segregación en el texto de su decretal Pervenit ad nos en términos de una consuetudo generalis ${ }^{12}$. La glosa ordinaria al Liber Extra (donde luego se incorporó el texto papal) señala que tal costumbre ha sido refrendada por el derecho canónico, citando otra decretal de Alejandro III, Cum dicat. Esta atiende a las necesidades espirituales de los leprosos que no pueden ser abandonados a su suerte en este aspecto y por ello estipula la constitución de iglesias y cementerios propios 'ubicumque tot simul leprosi sub communi vita fuerint congregati', lo que supone, según la glosa ordinaria, que 'cum aliis habitare non debent ${ }^{\prime 13}$. La glosa también explica que la segregación actúa 'etiam de iure veteris testamentis', remitiendo a C. 33 del Decretum de Graciano donde se trata la exclusión por lepra de Miriam, la hermana de Moisés, como figuración del tiempo necesario para la reinserción de los penitentes ${ }^{14}$. Como vemos, no hay referencias a una legislación de base sobre muerte civil.

De la misma manera, si abordamos una obra de consulta jurídica del s. XIV, como es el Dictionarium luris de Alberico de Rosate (... 1360), confirmamos que presenta muchas entradas sobre la lepra pero que no dan cuenta de una asimilación con la ficción de la mors civilis, y al mismo tiempo las entradas que tratan esta ficción legal se abstienen de remitirnos al estatuto de los leprosos, reenviando al lector a otro tipo de cuestiones, en general testamentarias ${ }^{15}$.

Ya dijimos antes que las menciones legales medievales que plantean la exclusión y muerte en vida de los enfermos de lepra están alejadas del ius commune (y, de hecho, Alberico no las cita). Así tenemos el referente más claro que es el Edicto de Rotario de 643 donde explícitamente se emplea la fórmula 'habere pro mortuo' implicando inhabilitaciones testamentarias:

176. Si quis leprosus effectus fuerit, et cognitum fuerit iudici vel populo certa rei veritas, et expulsus foris a civuitate aut casam suam, ita ut solus inhabitet, non sit ei licentia res suas alienare aut thingare cuilibet personae. Quia in eadem diae, quando a domo expulsus est, tanquam mortuus habetur. Tamen dum advixerit, de rebus quas reliquerit, pro mercedis intuitu nutriatur ${ }^{16}$.

8. Touati 1991a, p. 13. Ver también Tabuteau 2009; Brenner 2010.

9. Miller, Smith-Savage 2006, p. 23 y ss. También Tabuteau 2007; Carraro2013. Bériac 1988 señala el pago de derechos para la entrada en los leprosarios. Sobre su carácter cuasieclesiástico, ver Bériou 1991.

10. Tabuteau 2007.

11. Avril 1981. Sobre la discutida datación de la carta de Alejandro refrendada en Letrán III, ver Merzbacher 1967, p. 31 y ss.; Landau 1989, p. 569. Ver también Brundage 2000, p. 277.

12. 'Pervenit ad nos, quod cum hi, qui leprae morbum incurrunt, de consuetudine generali, a communione hominum separentur, nec uxores viros, nec viri uxores taliter aegrotantes, sequuntur', $\times 4.8 .1$ en la editio romana.

13. $\times 3.48 .2$, editio romana.

14. Hoc ipsum, quod canonum censura post septem annos remeare penitentem in pristinum statum precepit non electione proprii arbitrii sancti Patres, sed potius ex sentencia diuini iudicii sanxerunt. Nam legitur, quod Maria soror Aaron prophetissa, dum detractionis aduersum Moysen incurrisset delictum, illico stigmate leprae perfusa est, cumque peteret Moyses, ut emundaretur, precepit eam Dominus extra castra septem diebus egredi, et post emundationem rursus eam in castra admitti. Maria ergo soror Aaron caro intelligitur sacerdotis, que, dum superbiae dedita sordidissimis cogitationum maculatur contagiis, extra castra septem diebus, hoc est extra collegium sanctae ecclesiae septem annis proiciatur, ut post emundationem uiciorum loci uel pristinae dignitatis recipiat meritum', C. 33, q. 2, c. 11.

15. Dictionarium luris tam Civilis, quam Canonici, ad v. mors civilis y lepra.

16. MGH Leges Langobardorum, t. IV, 41. Ver Landau 1989, pp. 565-566. 
También tenemos un capitular de Carlomagno (789) que establece que los leprosos 'se non intermisceant alio populo'17, el pasaje anteriormente citado de Philippe de Beaumanoir y uno previo de Henry Bracton en su De legibus et consuetudinis Angliae (c. 16235) donde, tratando sobre las excepciones que caen sobre los que sufren 'lepra animae' (es decir, los excomulgados por herejía), se toma como punto de comparación la exclusión de los enfermos de lepra 'in corpore' con la expresión 'sicut leproso interdicitur communio gentium"18.

Este panorama disperso y, salvo por el caso del Edicto de Rotario, con una conexión poco precisa con la ficción de la muerte civil se confirma cuando se atiende a la bibliografía especializada, como el trabajo seminal de Brigitte Borgmann sobre el desarrollo jurídico medieval de la mors civilis donde se constata que la lepra no es una sedes materiae de esta cuestión. Sí lo son cuestiones como la deportación, la servitudo poenae, la excomunión, que pertenecen (con matices en el caso de la excomunión) al mundo de las penas mientras que el tratamiento jurídico de los leprosos no parecería convocar, en principio, a este tipo de lenguaje $\mathrm{e}^{19}$. Ya veremos después las ambigüedades del caso.

Por fuera del registro penal, por otro lado, la muerte civil tiene un desarrollo más amplio respecto del ingreso a la vida monacal, donde sí percibimos una ligazón mayor con el tratamiento de los leprosos. Pero se trata de una relación difícil de interpretar en términos de exclusión o inclusión. Bien podría tratarse de la aplicación de un mecanismo (ya habilitado por el derecho) de muerte civil para asegurar la exclusión de la comunidad del leproso considerado socialmente un muerto en vida y, como consecuencia de esta operación, el leprosario se va tiñendo de un color cuasi monacal. Bien podría tratarse, al contrario, de una concepción monacal del leprosario que, como cualquier otra congregación, supone el paso por unos mecanismos de integración como la muerte civil del monje y, como consecuencia de esta operación, el leproso se ve nominado con la expresión 'mors quant au siecle', como decía el texto de Philippe de Beaumanoir. Es una cuestión de perspectiva de análisis para la que resultan cruciales los estudios sobre la monaquización de las leproserías (que contaban con una organización similar a las congregaciones religiosas incluso con su división de regulares y conversi ${ }^{20}$ así como también la decisión final de la jerarquía eclesiástica de limitar este proceso de asimilación.

En definitiva, la relación documental entre muerte civil y lepra es problemática, por lo menos como para dar por sentado que la lepra implica la aplicación inmediata de esta ficción. Y, sin embargo, podemos detectar también huellas de que esta relación puede haber sido de sentido común en la Edad Media. A modo de ejemplo, cuando en el s. XV Alonso Fernández de Madrigal, "el Tostado", comenta el pasaje de Números sobre la hermana de Moisés no duda en conectar la lepra con la muerte civil: 'reputantur enim leprosi mortui quia expellebantur a castris, \& privabantur a communicatione aliorum [...] talis privatio dicitur mors civilis, \& ipsi qui lepram incurrunt, dicunt tunc moriuntur ${ }^{21}$.

Entonces, una primera aproximación a toda esta cuestión nos proporciona una imagen donde cunde la confusión y la ambigüedad, lo que desde otro punto de vista puede resultar lógico si se tiene en cuenta la serie de ambigüedades que en tiempos medievales caracterizaron a la conceptualización de la lepra y al tratamiento de sus enfermos, a saber:

a) La figura del leproso es particularmente ambigua en la cultura medieval en cuanto a los juicios de valor que sobre ella se formularon ${ }^{22}$. Por un lado, la lepra siempre aparece asociada a la vergüenza que se funda, no solo en los visibles efectos corporales y de contagio de la enfermedad, sino también en una tradición que se remonta hasta el Antiguo Testamento por la cual la lepra es vinculada con el pecado ${ }^{23}$. Esta ligazón se plantea tanto en la etiología de la enfermedad (su contracción se suele dar a partir de la comisión de ciertos pecados) ${ }^{24}$ como en sus consecuencias, como el hecho de que la sociedad medieval postule que los leprosos viven en un continuo ardor lujurioso por culpa de su mal, o el de que, según la tradición bíblica, Dios mismo castigue con la lepra a determinados pecadores ${ }^{25}$. En este contexto, la asimilación lepra/ herejía, facilitada por la variedad de síntomas paralela a la amplitud de variantes heréticas, tuvo un peso enorme en la cultura medieval ${ }^{26}$. Pero a la vez esta sociedad podía generar respecto del leproso una imagen positiva por cuanto se asociaba su penar con una imitatio Christi, una suerte de purgatorio en vida que experimentaba el leproso en este mundo y que le franqueaba las puertas del Paraíso en el trasmundo ${ }^{27}$.

Esta ambigüedad en la figura del leproso deriva en un tratamiento que siempre está a medio camino entre la caridad y la punición. Decíamos que la situación de los leprosos no debería, en principio, implicar el lenguaje de la pena. Sin embargo, el vocabulario y las prácticas llevadas adelante solían ser bastante más complejos. La detección del leproso se hace a través de un procedimiento que se conoce genéricamente como un 'iudicium leprosorum' en el que el enfermo es juzgado y condenado ${ }^{28}$ y existen incluso tribunales especializados como es el caso

17. MGH Legum Sectio II. Capitularia Regum Francorum, t. I, 69.

18. 'Item competit tenenti exceptio propter lepram animae petentis, ut si fuerit excommunicatus nominatim, sed non in genere, quia sicut lepra esse poterit in corpore ita et in anima, et sicut leproso interdicitur communio gentium, sic et excommunicato, et quod plus est, omnis actus legitimus', $\mathrm{H}$. Bracton 1640 lib. V, I.

19. Borgmann 1972.

20. Avril 1981.

21. Fernández de Madrigal 1728, p. 265 (In Numeros cap. XII, quaestio 42).

22. Brenner 2010.

23. Pichon 1988, p. 150; Touati 1991b, p. 102 y ss.; Moore 1976.

24. Sobre los conocimientos médicos medievales en torno de las formas de transmisión de la lepra, ver Bériac 1989 y Touati 1991b, pp. 127-185.

25. Miller, Smith-Savage 2006, p. 21, observan que, en el mundo cristiano oriental de lengua griega, los hombres de Iglesia distinguían entre alegoría y realidad y podían compatibilizar una descripción del pecado como lepra del alma con un tratamiento concreto de la enfermedad de corte asistencial y no punitivo.

26. Touati 1991 b, p. 106 ; Beriou 1991, p. 58.

27. Touati 1991 b, p. 188 y ss.; Touati 1991 a, p. 5 y ss.

28. Demaitre 2007, p. 53 plantea un interesante ejemplo al respecto en la Francia del s. XVI. 
de uno significativamente llamado La Purge que actuaba en la zona de Auvernia bajo tutela del rey de Francia, estudiado por Johan Picot ${ }^{29}$.

b) La propia situación de exclusión de los leprosos también está cargada de ambigüedad. En efecto, se concreta una expulsión de la communio gentium. Pero lo que la más reciente bibliografía señala insistentemente es que, al mismo tiempo, se produce la integración en una nueva comunidad, la leprosería, con sus propios vínculos, sus formas de organización, de liderazgo e incluso de representación ${ }^{30}$. En este punto, está claro que hay una diferencia fundamental entre la segregación en un leprosario y el aislamiento individual, situación esta última que suponía evidentemente una mayor desprotección: no es casual que los ordines que regulaban las misas de leprosos al final de la Edad Media (momento en el que la epidemia se resume y muchos leprosarios empiezan a volverse desiertos) recordaban a los sanos su deber de vigilia en las primeras horas de aislamiento a fin de evitar que el enfermo cayera en la desesperación y cometiera suicidio.

Por otro lado, a fin de calibrar la exclusión del leproso como un muerto en vida, debemos tener en cuenta que su "muerte" es para la vida secular y la comunidad de los vivos. Pero la Iglesia es una comunidad que incluye a vivos y a muertos. Se trata de una exclusión del mundo pero no de la Ecclesia. Y aquí nuevamente los ordines son interesantes toda vez que en las admoniciones finales que recibe el enfermo en la misa de leprosos se le recomienda que viva como un buen cristiano y que no se considere suprimido de las filas de la Iglesia ${ }^{31}$.

c) El tercer orden de ambigüedad que queremos señalar aquí atiende a la propia ficción de la muerte civil. Se trata de una figura en proceso de construcción en tiempos medievales y objeto de debate entre juristas que dudan respecto de su equiparación con la muerte natural. En este sentido, un punto crucial es el hecho de que, al no utilizarse únicamente en clave punitiva sino también para habilitar cambios de estado y condición, esta ficción de la muerte civil conoce una serie de limitaciones que la hacen compatible con la persistencia de algunas capacidades jurídicas, por un lado, y, por el otro, la tornan sujeta en sus efectos a las consecuencias que sigue teniendo la muerte natural en los individuos sobre los que se ha operado una muerte civil. Este tipo de limitaciones es lo que ha llevado a Brigitte Borgmann a plantear que es una ficción incompleta, que no se trata de una ficción legal en sentido técnico ${ }^{32}$.
En lo que concierne a la muerte civil del que ingresa a un monasterio, la situación más próxima, como dijimos, a la de los leprosos, el tratamiento de glosadores y comentadores recalca que no se trata de muertos propiamente dichos, toda vez que mantienen capacidades jurídicas (como el derecho a testificar en juicio), algunas incluso patrimoniales. Esta distancia cuestionable entre mors civilis y mors naturalis agrega, a nuestro entender, una cuota de ambigüedad que complica el seguimiento del tratamiento del leproso como muerto en vida ${ }^{33}$.

d) El último punto de ambigüedad que queremos indicar resulta de la aplicación a la cuestión de la lepra de un rasgo general del panorama jurídico y judicial de la Europa medieval. Nos referimos a las distancias entre doctrina y práctica que dificultan seriamente plantear tendencias o líneas de desarrollo a largo plazo. Nombremos dos ejemplos para dar cuenta de este punto.

En primer lugar, como señalamos, la tradición del ius commune parece prescindir del escenario de la lepra como sedes materiae para la construcción de la ficción legal de la muerte civil. Las citas legales o jurídicas que hemos señalado son bien tempranas o se manejan (y en términos de gran vaguedad) en el registro de la costumbre ${ }^{34}$. No obstante, la práctica médico-jurídica del iudicium leprosorum, si consideramos lo que ocurre en un tribunal real como La Purge, sigue un procedimiento que moviliza los mecanismos más modernos del desarrollo jurídico de la época: fama denunciante, inquisitio, pericias, etc. ${ }^{35}$.

Otro escenario de distancia doctrina/práctica viene dada por la materia 'de conjugio leprosorum'. Por un lado, en sede canónica hallamos una postura rigorista, en perfecta coherencia con el desarrollo que hacía del matrimonio un sacramento y de la indisolubilidad uno de sus rasgos fundamentales, que negaba a la contracción de la lepra como una razón válida para la desaparición del vínculo conyugal pues solo la muerte podía tener ese efecto ${ }^{36}$. Pero este rigorismo canónico va más allá pues tampoco considera que la lepra pueda suspender el débito conyugal que se deben marido y mujer en función del ius in corpus que ejerce cada uno sobre el cuerpo del otro (débito carnal que queda suspendido en otros casos que sí habilitan una separación quoad thorum como el adulterio carnal o el espiritual) ${ }^{37}$. Vale decir, para el derecho canónico el cónyuge enfermo tiene derecho a exigir el mantenimiento de relaciones sexuales con el cónyuge sano, incluso cuando por cuestiones prácticas de orden sanitario se puede liberar a este último del deber de cohabitación (de acuerdo con las condiciones que

29. Picot 2012.

30. Carraro 2013, p. 21. También Miller, Smith-Savage 2006, p. 23.

31. Bériac 1985.

32. Borgmann 1972, pp. 114-115.

33. Una cuota mayor de ambigüedad la aporta la distinción entre hijos nacidos antes y después de contraída la lepra (una distinción muy frecuente en los tratamientos jurídicos medievales en torno de la transmisión de penas en referencia al momento del crimen, cf. Morin 2009, pp. 223-326). Según Bériou 1991, p. 72 los hijos procreados tras la contracción de la enfermedad son considerados hijos nacidos fuera de todo vínculo de parentesco terrestre, lo que explica que no puedan heredar.

34. Miller, Smith-Savage 2006, pp. 24-25, señalan que la exclusión legal se da en las sociedades más influenciadas por el "derecho consuetudinario germánico" que por la doctrina cristiana y el corpus justinianeo.

35. Picot 2012.

36. Landau 1989, pp. 565-574; Orlando 2013, pp. 251-255.

37. Un ejemplo de esta fuerza mayor del casamiento por sobre la enfermedad lo hallamos en Partidas IV.2.7. Acerca de la lepra en la obra jurídica alfonsí, ver Ortuño 1992, p. 149; Morin 2009, pp. 234-241. Sobre las elaboraciones jurídicas en torno del derecho al cuerpo del cónyuge, ver Testuzza 2012; Madero 2015. Sobre la lepra y la continuación del lazo matrimonial, ver Gaudemet 1987, p. 258; Bériou 1991, pp. 71-72; Brundage 2000, p. 338. 
imponga el establecimiento donde se recluya al leproso, si es el caso) ${ }^{38}$.

Esta postura, que se sanciona en las Decretales ${ }^{39}$, supone un "integracionismo" a ultranza que sabotea indudablemente el proceso de transformación del leproso en un muerto en vida y opone serias dificultades a la operatividad de la ficción jurídica de la muerte civil a su respecto. Los comentadores, sin embargo, considerarán la posibilidad de excepciones en función del peligro de contagio (incluyendo referencias a textos médicos donde se afirma un desigual riesgo de contagio entre varones y mujeres en unos términos que, podemos ya imaginarnos, eran particularmente discriminatorios para ellas) ${ }^{40}$. El hecho es que, mientras la doctrina canónica no parece admitir reparos en el mantenimiento del matrimonio del leproso con todas sus posibilidades y derechos, la práctica judicial puede terminar habilitando la separación (tal como Ermanno Orlando detectó en la justicia episcopal en la Venecia del s. $\mathrm{XV})^{41}$, reforzando así la efectiva exclusión de los leprosos.

Con este cúmulo de ambigüedades lo que se busca señalar es la complejidad de una temática que no se resuelve reproduciendo ni impugnando acríticamente un lugar común. La relación entre lepra y muerte civil ha resultado ser más problemática de lo que estábamos habituados a sostener y nos aleja de la certeza con la que asegurábamos otrora que una implicaba automáticamente la otra. Una historia de la lepra medieval que conjugue el estudio de las prácticas de segregación con el de la aplicabilidad y limitaciones de las ficciones jurídicas en el derecho bajomedieval es una tarea todavía en ciernes.

Ahora bien, esta perspectiva implica diferenciarse de dos enfoques hasta ahora ensayados. Por un lado, una historiografía de la marginalidad y la exclusión que suele mirar los documentos jurídicos con ojos etnográficos pero sin atender a la construcción jurídico-institucional: la historiografía de la sociedad represora se ha montado sobre el peso de los imaginarios sociales y no sobre el estudio de específicos mecanismos institucionales que siempre implican una laboriosa construcción y que deben llevar adelante cierta lógica de aplicabilidad para ser eficaces. Por el otro lado, una historiografía anti leyenda negra que insiste en relativizar el estereotipo del leproso perseguido y marginado rescatando las prácticas de integración (sea la permanencia de contactos con la sociedad de los sanos, sea atendiendo a las formas de constitución de la nueva comunidad de inserción dada por el leprosario). Esta historiografía descree de la muerte civil del leproso (o por lo menos de sus alcances) pero no ofrece una interpretación de conjunto del tratamiento legal de la lepra medieval que dimensione efectivamente las operaciones jurídicas puestas en juego y sus limitaciones.

Hemos cruzado en este breve trabajo lo planteado por la bibliografía especializada con lo que ofrece el arco de fuentes jurídicas en torno de la muerte civil de los leprosos medievales. La intención fue desbrozar un terreno de trabajo, tarea necesaria para cualquier diagnóstico de situación bien encaminado. La apuesta que se propone, una vez despejado el panorama, es centrar el análisis en función de los límites de ficcionalización en el mundo medieval: no se trata tanto de calibrar el rigor de la exclusión o la solidez de la (re)inclusión, como de relevar las limitaciones que los mismos mecanismos puestos a operar oponen a cualquier elaboración que habilite un tratamiento determinado respecto de este sector de la sociedad medieval.

38. Testuzza 2012.

39. La Glosa Ordinaria a la decretal Pervenit ad nos declara errónea la costumbre de romper el vínculo y habilitar nuevo matrimonio ('sed in hoc quod viri sani non sequuntur uxores, vel econverso, mala erat consuetudo'), como ocurría según el Concilio de Compiegne de 757 (c. 19): 'Si quis leprosus mulierem habeat sanam, si vult ei donare comiatum ut accipiat virum, ipsa femina, si vult, accipiat. Similiter et vir', MGH Legum Sectio II. Capitularia Regum Francorum, t. I, 39.

40. Ver las referencias de corte médico a esta cuestión por Pedro Paludano en su comentario al cuarto libro de las Sentencias de Pedro Lombardo, dist. XXXII.

41. Orlando 2013 , p. 256 y ss. 
- Alfonso X, Las Siete Partidas, Salamanca: Andrea de Portonaris, 1555 [edición de Gregorio López, en reproducción anastástica de la editorial del Boletín Oficial del Estado, Madrid, 1974].

- Avril, Joseph, “Le III concile du Latran et les communautés de lépreux", Revue Mabillon 60 (1981) pp. 21-76.

- Bériac, Françoise, Histoire des lépreux au Moyen Âge. Une société d'exclus, París: Imago, 1988.

- Bériac, Françoise, " "Mourir au monde». Les ordines de séparation des lépreux en France aux XVe et XVle siècles", Journal of Medieval History 11 (1985) pp. 245-268.

- Bériou, Nicole, "Les lépreux sous le regard des prédicateurs d'après les collections de sermons ad status du XIlle siècle", en François Touati \& Nicole Bériou, Voluntate dei leprosus. Les lépreux entre conversion et exclusion au Xlle et XIIle siècles, Spoleto, Centro Italiano di Studi sull' Alto Medioevo, 1991, pp. 33-80.

- Borgmann, Brigitte, "Mors civilis: die Bildung des Begriffs im Mittelalter und sein Fortleben im französchen Recht der Neuzeit", lus commune, 4 (1972), pp. 81-157.

- Bracton, Henry, De Legibus et Consuetudinibus Angliae, Londres, Flesher \& Young, 1640.

- Brenner, Elma, "Recent Perspectives on Leprosy in Medieval Western Europe", History Compass 8/5 (2010) pp. 388-406.

- Brundage, James, La ley, el sexo y la sociedad cristiana en la Europa medieval, México, Fondo de Cultura Económica, 2000.

- Carraro, Silvia, "Oltre la morte sociale: il lebbrosario di Venezia nel XIII secolo", en Giuseppina de Sandre Gasparini, (ed.), Malsani. Lebbra e lebbrosi nel medieovo, Verona, (Quaderni di storia religiosa, 19), 2013, pp. 229-250.

- Demaitre, Luke, Leprosy in Premodern Medicine: a Malady of the Whole Body, Baltimore, The Johns Hopkins University Press, 2007.

- Fernández de Madrigal, Alonso. Commentaria in Primam Partem Numerorum, t. V, Venecia, Typographia Balleoniana, 1728.

- Gaudemet, Jean, El matrimonio en Occidente, Madrid, Taurus, 1993.

- Graciano, Corpus luris Canonici, editio Lipsiensis secunda post Acuilii Ludovici Richteri curas instruxit Acuilius Friedberg, Graz: Akademische Druck. u. Verlagsanstalt, 1958.

- Gregorio IX, Decretales D. Gregorii Papae IX, Roma, 1582.

- Landau, Peter, "Die Leprakranken im mittelalterlichen kanonischen Recht", en Schwab, Dieter (ed.), Staat, Kirche, Wissenschaft in einer pluralistischen Gesellschaft: Festschrift zum 65. Geburtstag von Paul Mikat, Berlín, 1989, pp. 169-177.

- Madero, Marta, La loi de la chair. Le droit au corps du conjoint dans l'œuvre des canonistes (Xlle-XVe siècles), París, Publications de la Sorbonne, 2015.

- Merzbacher, Friedrich, "Die Leprosen im alten kanonischen Recht", ZRG Kan. Abt. 53 (1967) pp. 27-45.

- Miller, Timothy, Smith-Savage, Rachel, "Medieval Leprosy Reconsidered”, International Social Science Review 81, 1/2 (2006) pp. 16-28.

- Moore, Robert, "'Heresy as Disease', The Concept of Heresy in the Middle Ages”, en W. Lourdaux and D. Verhelst (eds.), The Concept of Heresy in the Middle Ages, Leuven University Press, 1976, pp. 1-12.

- Moore, Robert, La formación de una sociedad represora. Poder y Disidencia en la Europa Occidental, 950-1250, Barcelona, Crítica, 1989.

- Monumenta Germaniae Historica. Legum Sectio II. Capitularia Regum Francorum, t. I, Hannover, Hahn, 1883

- Monumenta Germaniae Historica. Leges Langobardorum, t. IV, Pertz, Georg (ed.), Hannover: Hahn, 1868.

- Morin, Alejandro, Pecado y delito en la Edad Media. Estudio de una relación a partir de la obra jurídica de Alfonso el Sabio, Córdoba, Ordia Prima, 2009. 
- Orlando, Ermanno, "Et lepra superveniens non dissolvit matrimonium. Malattia contagiosa e separazione (da alcuni casi veneziani del XV secolo)" , en Giuseppina de Sandre Gasparini (ed.), Malsani. Lebbra e lebbrosi nel medieovo, Verona (Quaderni di storia religiosa, 19), 2013, pp. 251-260.

- Ortuño Sánchez-Pedreño, José María "Tratamiento jurídico de la enfermedad en las Partidas", Glossae. European Journal of Legal History 3 (1992) pp. 135-164.

- Pedro Paludano, In quartum Sententiarum, Venecia, 1493.

- Philippe de Beaumanoir, Coutumes de Beauvaisis (Am. Salmon, ed.), París, Alphonse Picard et fils, 1900.

- Pichon, Geneviève "La lèpre et le péché", Nouvelle Revue de Psychanalyse 38 (1988) pp. 147-157.

- Picot, Johan, "«La Purge»: une expertise juridico-médicale de la lèpre en Auvergne au Moyen Âge", Revue historique 662/2 (2012) pp. 292-321.

- Rosate, Alberico de, Dictionarium Iuris tam Civilis, quam Canonici, Venecia: apud Guerreos fratres et socios, 1573 (ed. anast. de 1971 , Turín: Bottega d'Erasmo).

- Tabuteau, Bruno "La lèpre dans l'Angleterre médiévale : À propos du livre de Carole Rawcliffe, Leprosy in Medieval England", Memini [online] 13 (2009), http://memini.revues.org/192

- Tabuteau, Bruno, "Historical Research Developments on Leprosy in France and Western Europe", en Barbara Bowers (ed.), The Medieval Hospital and Medical Practice, Burlington, Ashgate, 2007, pp. 41-56.

- Testuzza, Maria Sole "De coniugio leprosorum: antiche questioni di bio-diritto", Forum Historiae luris, (2012) http://www.forhistiur.de/201211-testuzza/

- Touati, François-Olivier, "Les léproseries aux Xllème et Xllème siècles, lieux de conversion?", en Bériou, Nicole \& Touati, François-Olivier, Voluntate dei leprosus. Les lépreux entre conversion et exclusion au Xlle et XIlle siècles, Spoleto, Centro Italiano di Studi sull' Alto Medioevo, 1991 , pp. 1-32.

- Touati, François-Olivier, Maladie et Société au Moyen Age. La lèpre, les lèpreux et les léproseries dans la province ecclésiastique de Sens jusqu'au milieu du XIVe siècle, París-Bruselas, De Boeck Université, 1991b.

- Vallejo, Jesús, "Vida castellana de la muerte civil en torno a la Ley cuarta de Toro”, Historia. Instituciones. Documentos 31 (2004) pp. 671-686. 